\title{
Male patients presenting with rapidly progressive puberty associated with malignant tumors
}

\author{
Soo Jung Kim, $M D^{1}$, \\ A Ra Ko, MD', \\ Mo Kyung Jung, MD', \\ Ki Eun Kim, MD', \\ Hyun Wook Chae, MD', \\ Duk Hee Kim, MD, PhD², \\ Ho-Seong Kim, MD, PhD', \\ Ah Reum Kwon, MD ${ }^{1}$
}

'Department of Pediatrics, Severance Children's Hospital, Endocrine Research Institute, Yonsei University College of Medicine, Seoul, ${ }^{2}$ Sowha Children's Hospital, Seoul, Korea
In males, precocious puberty (PP) is defined as the development of secondary sexual characteristics before age 9 years. PP is usually idiopathic; though, organic abnormalities including tumors are more frequently found in male patients with PP. However, advanced puberty in male also can be an important clinical manifestation in tumors. We report 2 cases of rapidly progressive puberty in males, each associated with a germ-cell tumor. First, an 11-year-old boy presented with mild fever and weight loss for 1 month. Physical examination revealed a pubertal stage of G3P3 with 10-mL testes. Investigations revealed advanced bone age (16 years) with elevated basal luteinizing hormone and testosterone levels. An anterior mediastinal tumor was identified by chest radiography and computed tomography, and elevated a-fetoprotein (AFP) and $\beta$-human chorionic gonadotropin ( $\beta$-hCG) levels were noted. Histopathologic analysis confirmed a yolk-sac tumor. Second, a 12-year-old boy presented with diplopia, polydipsia, and polyuria for 4 months. Physical examination revealed a pubertal stage of G3P3 with 8-mL testes. Bone age was advanced (16 years) and laboratory tests indicated panhypopituitarism with elevated testosterone level. A mixed germ-cell tumor was diagnosed with elevated AFP and $\beta$-hCG levels. Of course, these patients also have other symptoms of suspecting tumors, however, rapidly progressive puberty can be the more earlier screening sign of tumors. Therefore, in male patients with accelerated or advanced puberty, malignancy should be considered, with evaluation of tumor markers. In addition, advanced puberty in male should be recognized more widely as a unique sign of neoplasm.

Keywords: Puberty, Neoplasms, Germ-cell tumor

\section{Introduction}

Precocious puberty (PP) can be defined as sexual maturation that occurs in children 2.5 standard deviations of the mean earlier than in the normal population. The underlying causes of PP are usually benign or idiopathic with no evidence of organ lesions, especially in central precocious puberty and in girls ${ }^{1)}$. While PP is relatively rare in boys, it is more likely to be associated with underlying diseases, such as congenital adrenal hyperplasia, McCune-Albright syndrome and several kinds of tumors ${ }^{2}$. It is therefore important to reliably identify the cause underlying each case of PP in boys. However, even when cases do not meet criteria for PP, accelerated pubertal velocity or advanced puberty can also reflect underlying disease. The pubertal course was considered accelerated if the transition from Tanner pubertal stage 2 to 3 occurred within less than 1.5 years $^{3)}$. Here, we report 2 cases of rapidly progressive puberty in boys caused by neoplasm.
Received: 28 August, 2015

Revised: 9 September, 2015

Accepted: 2 October, 2015

Address for correspondence:

Ah Reum Kwon, MD

Department of Pediatrics, Severance

Children's Hospital, Endocrine

Research Institute, Yonsei University

College of Medicine, 50-1 Yonsei-ro,

Seodaemun-gu, Seoul 03722, Korea

Tel: +82-2-2228-2050

Fax: +82-2-393-9118

E-mail: armea@yuhs.ac
ISSN: 2287-1012(Print)

ISSN: 2287-1292(Online) 


\section{Case reports}

\section{Case 1}

An 11.7-year-old boy initially visited a local pediatric clinic because of mild fever, cough, and weight loss of about $4 \mathrm{~kg}$ in 1 month. In his physical examination, tachycardia was also noted. The patient was referred to our pediatric endocrinology clinic for differential diagnosis of hyperthyroidism. He had no perinatal history. His past medical history and family medical history were not relevant except for a diagnosis of autism at 4-5 years old. He did not show signs of hyperthyroidism, symptoms such as sweating, hot flash, tremor, and fatigue, but dyspnea was noted following exercise. In a physical examination, his height and weight placed him in the 75 th-90th $(151 \mathrm{~cm})$ and the 10th-25th percentiles $(34.2 \mathrm{~kg})$, respectively, for his age and sex. He was found to have a Tanner pubertal stage of P3 with testicular volumes of $10 \mathrm{~mL}$ in both testicles. His pulse rate was 90-100 per minute with tachycardia, but he had no goiter or exophthalmos.

A basal thyroid-function test was conducted for differential diagnosis of hyperthyroidism and chest radiography was performed because of the cough and mild fever. In addition, because of the patient's advanced Tanner pubertal stage, hormonal studies were also performed. Thyroid function was found to be normal (T3, $0.52 \mathrm{ng} / \mathrm{mL}$; normal range, $0.58-1.59$ $\mathrm{ng} / \mathrm{mL}$; free T4, $1.28 \mathrm{ng} / \mathrm{dL}$; normal range, $0.70-1.48 \mathrm{ng} / \mathrm{dL}$; and thyroid-stimulating hormone, $0.95 \mu \mathrm{IU} / \mathrm{mL}$; normal range, $0.35-4.49 \mu \mathrm{IU} / \mathrm{mL}$ ) and thyroid-stimulating antibody was also negative. The patient's luteinizing hormone (LH) level was appropriate for his age, but testosterone was elevated compared to normal values for the patient's age and sex $(\mathrm{LH}, 0.61 \mathrm{mIU} /$ $\mathrm{mL}$; normal range, $0.2-5.0 \mathrm{mIU} / \mathrm{mL}$; testosterone, $509.8 \mathrm{ng} /$
$\mathrm{dL}$; normal range, 100-320 ng/dL). His bone age was advanced, estimated to be 16 years and to sum it up the results, he was just suspected rapidly progressive or advanced puberty. However, the initial chest radiography revealed multiple lung and pleural nodules and masses with right pleural effusion (Fig. 1). A chest computed tomography scan was performed and revealed an anterior mediastinal mass $(5.4 \mathrm{~cm} \times 4.5 \mathrm{~cm} \times 6.0 \mathrm{~cm})$ with lymph node, lung, and pleural metastases, suggesting a malignant germcell tumor (GCT). Levels of tumor biomarkers were elevated, including a-fetoprotein (AFP), 20,509.21 ng/mL (normal range, $0.6-3.9 \mathrm{ng} / \mathrm{mL}$ ) and $\beta$-human chorionic gonadotropin ( $\beta$-hCG), $60 \mathrm{mIU} / \mathrm{mL}$ (normal range, $<25 \mathrm{mIU} / \mathrm{mL}$ ). Histopathologic examination of the mass by gun biopsy indicated a yolk-sac tumor.

The patient was scheduled for chemotherapy with bleomycin, cisplatin, and etoposide and during treatment, levels of serum AFP and $\beta$-hCG normalized in 3 months, but the mediastinal mass did not respond to treatment (Table 1). The patient then underwent an autologous peripheral blood stem-cell transplantation and wedge resection of the left lung. After 1 year, his height measured $153 \mathrm{~cm}$ (lower than the 3th percentile for adult height) and he had a closed epiphyseal plate.

\section{Case 2}

A 12.2-year-old boy presented with diplopia, polyuria, and polydipsia for 4 months and was referred to our hospital for further evaluation. He was diagnosed with a pineal-gland mixed GCTs without metastasis (Fig. 2). After surgical removal of the tumor, he was referred to our pediatric endocrinology clinic for pituitary hormone replacement. His past and family medical histories were unremarkable except for his pineal-gland mixed GCTs with elevated AFP (35.7 ng/mL; normal range,

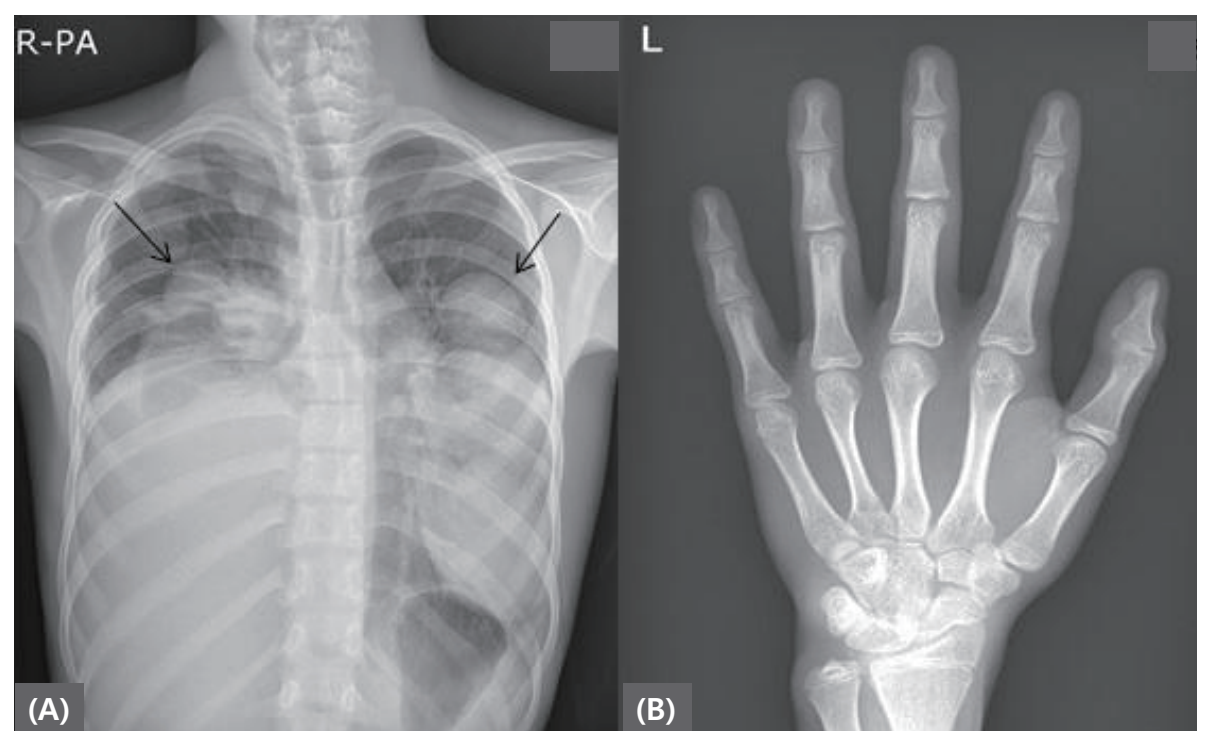

Fig. 1. (A) Chest radiograph showing multiple lung and pleural nodules and masses with right pleural effusion. (B) Left hand bone age radiograph at diagnosis. The arrow indicates lung and pleural nodules and masses. 


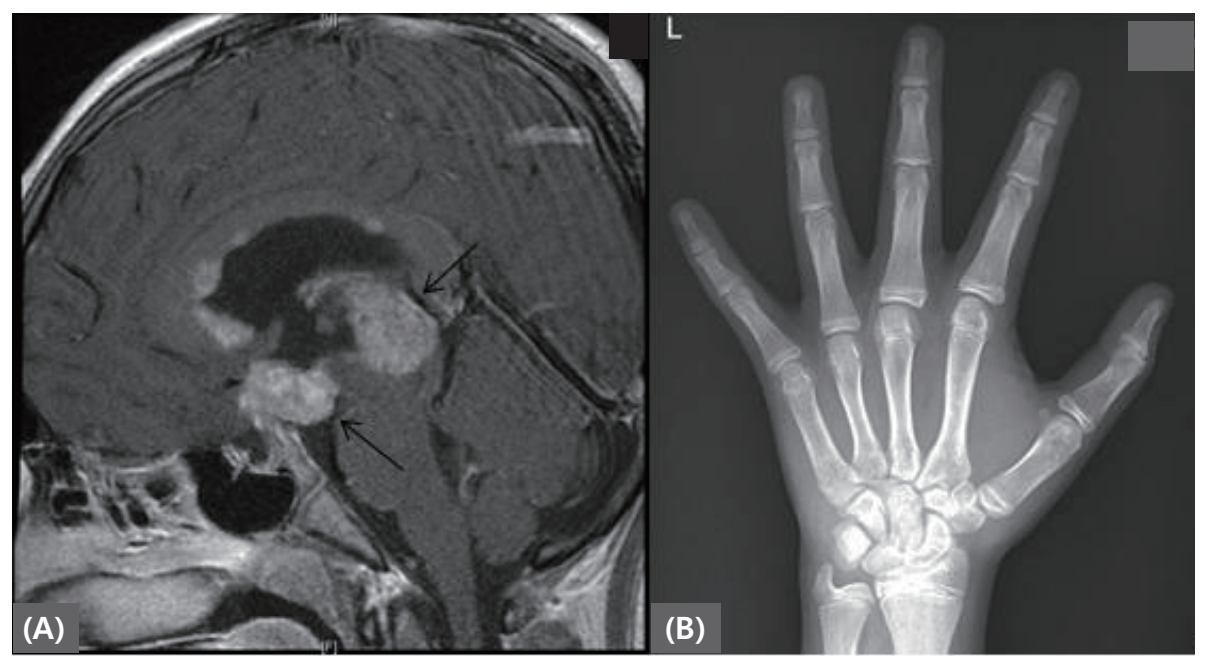

Fig. 2. (A) Brain magnetic resonance imaging revealing mass lesions at pineal gland and suprasellar area. (B) Left hand bone age radiograph at diagnosis. The arrow indicates pineal gland and suprasellar area masses.

Table 1. Descriptive characteristics and hormone levels of 2 patients with advanced puberty

\begin{tabular}{|c|c|c|}
\hline Characteristic & Patient 1 & Patient 2 \\
\hline Height (cm) & 151 (75th-90th percentile) & 155 (50th-75th percentile) \\
\hline Weight (kg) & 34.2 (10th-25th percentile) & 57 (90th percentile) \\
\hline Chronological age (yr) & 11.7 & 12.2 \\
\hline Bone age (yr) & 16 & 16 \\
\hline \multicolumn{3}{|l|}{ Basal level } \\
\hline $\mathrm{LH}(\mathrm{mlU} / \mathrm{mL})$ & 0.61 & 0.36 \\
\hline $\mathrm{FSH}(\mathrm{mlU} / \mathrm{mL})$ & $<0.2$ & $<0.2$ \\
\hline Testosterone (ng/dL) & 509.8 & 959.8 \\
\hline$\beta-h C G(m I U / m L)$ & 60 & 2,642 \\
\hline AFP $(n g / m L)$ & $20,509.21$ & 35.7 \\
\hline \multicolumn{3}{|c|}{1 Month after chemotherapy } \\
\hline$\beta-h C G(m I U / m L)$ & $<0.1$ & 4 \\
\hline $\operatorname{AFP}(n g / m L)$ & $1,434.7$ & - \\
\hline \multicolumn{3}{|c|}{2 Months after chemotherapy } \\
\hline$\beta-h C G(m I U / m L)$ & $<0.1$ & $<0.1$ \\
\hline $\operatorname{AFP}(n g / m L)$ & 14.33 & 3.38 \\
\hline \multicolumn{3}{|c|}{3 Months after chemotherapy } \\
\hline $\mathrm{LH}(\mathrm{mlU} / \mathrm{mL})$ & 3.68 & 0.26 \\
\hline $\mathrm{FSH}(\mathrm{mlU} / \mathrm{mL})$ & 9.2 & $<0.2$ \\
\hline Testosterone (ng/dL) & - & $<2.5$ \\
\hline$\beta-h C G(m l U / m L)$ & $<0.1$ & $<0.1$ \\
\hline $\operatorname{AFP}(n g / m L)$ & 3.39 & 1.49 \\
\hline
\end{tabular}

LH, luteinizing hormone; FSH, follicle-stimulating hormone; $\beta$-hCG, $\beta$-human chorionic gonadotropin; AFP, a-fetoprotein.

0.6-3.9 ng/mL) and serum $\beta$-hCG $(2,642 \mathrm{mIU} / \mathrm{mL}$; normal range, $<25 \mathrm{mIU} / \mathrm{mL}$ ). On physical examination, the patient's height and weight placed him in the 50 th-75th $(155 \mathrm{~cm})$ and 90th percentiles $(57 \mathrm{~kg})$, respectively. He was noted to have an advanced Tanner pubertal stage of $\mathrm{P} 3$ with testicular volumes of 8-mL for both testicles.

Before surgery, a basal thyroid-function test showed hypothyroidism, with levels of T3 $(0.65 \mathrm{ng} / \mathrm{mL}$; normal range, $0.58-1.59$ $\mathrm{ng} / \mathrm{mL})$, free T4 (0.51 ng/dL; normal range, $0.70-1.48 \mathrm{ng} / \mathrm{dL})$, and thyroid-stimulating hormone $(1.01 \mu \mathrm{IU} / \mathrm{mL}$; normal range,
$0.35-4.49 \mu \mathrm{IU} / \mathrm{mL})$. Level of adrenocorticotropic hormone and cortisol was $4.08 \mathrm{pg} / \mathrm{mL}$ (normal range, $10-60 \mathrm{pg} / \mathrm{mL}$ ) and $1.5 \mu \mathrm{g} / \mathrm{dL}$ (normal range, $5-23 \mu \mathrm{g} / \mathrm{dL}$ ), respectively. His LH level was normal for his age and sex, but testosterone was elevated ( $\mathrm{LH}, 0.36 \mathrm{mIU} / \mathrm{mL}$; normal range, $0.2-5.0 \mathrm{mIU} / \mathrm{mL}$; testosterone, $959.8 \mathrm{ng} / \mathrm{dL}$; normal range, 100-320 ng/dL). His bone age was also advanced, at 16 years. After fluid restriction for differential diagnosis of diabetes insipidus, urine osmolality was $169 \mathrm{mOsm} / \mathrm{kg}$ while serum osmolality was $310 \mathrm{mOsm} /$ $\mathrm{kg}$, consistent with diabetes insipidus. Based on physical 
examination and laboratory findings, the final diagnosis was mixed GCTs, multiple pituitary hormone insufficiency after surgery, and rapidly progressive puberty.

The patient was started on synthyroid ( $0.1 \mathrm{mg}$ once daily), hysone ( $20 \mathrm{mg}$ twice daily), and minirin $(0.15 \mathrm{mg}, 0.1 \mathrm{mg}, 0.1$ $\mathrm{mg}$, and $0.1 \mathrm{mg}$, daily). He received chemotherapy according to the KSPNO G082 protocol and was then treated with craniospinal irradiation with a total local dose of $39 \mathrm{~Gy}$. During treatment, serum AFP and $\beta$-hCG levels normalized in 2 months and his testosterone level normalized in 3 months (Table 1). After 1 year, he reached an adult height $(157 \mathrm{~cm}$, lower than the 3 th percentile for adults) and had a closed epiphyseal plate.

\section{Discussion}

Although the cause of PP is usually idiopathic or benign, malignancy can also cause PP. This possibility should be considered during evaluations of puberty, in particular, among young, male children and in cases of pseudo- $\mathrm{PP}^{4)}$. Of the various kinds of tumors that can cause PP by inducing excessive sex-hormone secretion, $\beta$-hCG-secreting GCTs may be the most commonly associated with $\mathrm{PP}^{5}$. GCTs are relatively rare and represent only $3 \%$ of all malignant tumors in childhood ${ }^{6}$. These are further divided into gonadal and extragonadal GCTs, and among the extragonadal GCTs, the central nervous system (CNS), retroperitoneum, and mediastinum are the most frequent sites. The initial clinical manifestations of GCTs depend on their particular location. CNS GCTs usually involve the hypothalamus and pituitary gland and can lead to diabetes insipidus, growth retardation and visual-field defects ${ }^{6}$. However, the other common sites for extragonadal GCTs do not have unique, distinguishing clinical features and so the diagnosis is sometimes delayed ${ }^{7}$. Fortunately, although only a small proportion of GCTs produce $\beta$-hCG, $\mathrm{PP}$ in boys may be a unique clinical manifestation of $\beta$-hCGsecreting GCTs. Because $\beta$-hCG and LH possess an identical $\alpha$-subunit and a similar $\beta$-subunit, the autonomous secretion of $\beta$-hCG can stimulate Leydig cells to produce testosterone ${ }^{8)}$. In girls, elevated $\beta$-hCG secretion alone does not induce PP because follicle-stimulating hormone is required for ovarian estradiol production ${ }^{5}$. Therefore, pseudo-PP may be a clinical manifestation of $\beta$-hCG-secreting GCTs only in boys.

Even when patients do not meet the exact criteria for PP, subthreshold advanced puberty can still be caused by a tumor. According to Wendt et al. ${ }^{4}$, in 24 patients with PP caused by neoplasm, 29\% had normal pubertal timing but accelerated pubertal velocity, as reflected by a more rapid progression through Tanner stages and more advanced bone age (more than 2 standard deviations above chronological age). This demonstrates that recognizing pathological variants of puberty requires not only age-based definitions of $\mathrm{PP}$, but also a thorough understanding of the normal spectrum of pubertal development. In particular, GCTs occur most frequently in the second decade of life and most children have begun puberty by this time ${ }^{9)}$. In our 2 cases, patients were 11 and 12 years old and did not meet age-based definitions of PP; however, they had rapidly progressive puberty and malignancy. Of course, these patients had other symptoms suggestive of malignancy such as mild fever, weight loss, chronic cough, and diplopia. However, in the first case, these symptoms were not specific to the tumor, and the patient was treated for bronchitis for 1 month at his local clinic, delaying the diagnosis of a tumor. Lin et al. ${ }^{6}$ reported that about $60 \%$ of the patients with $\beta$-hCG-secreting GCTs exhibit symptoms and signs for more than 6 months before receiving the proper diagnosis. The authors suggested that a failure to recognize the initial clinical manifestations may partly account for these delayed diagnoses ${ }^{6,7)}$. In our cases, accelerated or advance puberty can be an earlier clinical symptom than mild fever, weight loss and diplopia, and then not a typical pubertal development can be an initial screening manifestation. Therefore, concern regarding rapid growth and advanced puberty is necessary regardless of the diagnostic criteria used for PP.

When tumors are diagnosed, tumor treatment should become a priority over other treatment. However, normal growth and puberty should also be a target of interventions in children. After complete remission, the heights of our patients were evaluated, and unfortunately, the epiphyseal plate had already closed in both patients. They reached their adult height already, below the 3rd percentile. Neoplasm-induced pubertal acceleration and advanced puberty resulted in a too-short adult height, which may negatively impact their confidence ${ }^{10)}$. Therefore, patients who have a malignancy such as a $\beta$-hCGsecreting tumor or a sex-steroid-secreting tumor, such as an adrenocortical carcinoma, should be considered additionally for an evaluation of pubertal stages and growth status. In addition, a patient's expected adult height is too short, sufficient explanation and moral support should be provided. Furthermore, because additional treatments may also be needed, a multidisciplinary approach is important.

In conclusion, we propose that male patients with rapid progressive or advanced puberty (not only PP) should be evaluated for signs of possible malignancy, and if malignancy is suspected, it should be considered with tests including the measurement of tumor biomarkers such as $\beta$-hCG. In addition, if a patient is diagnosed with a malignant tumor, multidisciplinary treatment should be implemented, targeting the tumor, growth, and puberty.

\section{Conflict of interest}

No potential conflict of interest relevant to this article was reported.

\section{References}

1. Berberoglu M. Precocious puberty and normal variant puberty: definition, etiology, diagnosis and current management. J Clin Res Pediatr Endocrinol 2009;1:164-74. 
2. Low LC, Wang Q. Gonadotropin independent precocious puberty. J Pediatr Endocrinol Metab 1998;11:497-507.

3. Lazar L, Pertzelan A, Weintrob N, Phillip M, Kauli R. Sexual precocity in boys: accelerated versus slowly progressive puberty gonadotropin-suppressive therapy and final height. J Clin Endocrinol Metab 2001;86:4127-32.

4. Wendt S, Shelso J, Wright K, Furman W. Neoplastic causes of abnormal puberty. Pediatr Blood Cancer 2014;61:66471.

5. Schwabe J, Calaminus G, Vorhoff W, Engelbrecht V, Hauffa BP, Gobel U. Sexual precocity and recurrent beta-human chorionic gonadotropin upsurges preceding the diagnosis of a malignant mediastinal germ-cell tumor in a 9-year-old boy. Ann Oncol 2002;13:975-7.

6. Lin CM, Lee CT, Tung YC, Wu MZ, Tsai WY, Yang YL, et al. Endocrine dysfunction in Taiwanese children with human chorionic gonadotropin-secreting germ cell tumors. J Formos Med Assoc 2014;113:102-5.
7. Crawford JR, Santi MR, Vezina G, Myseros JS, Keating RF, LaFond DA, et al. CNS germ cell tumor (CNSGCT) of childhood: presentation and delayed diagnosis. Neurology 2007;68:1668-73.

8. Schneider DT, Calaminus G, Gobel U. Diagnostic value of alpha 1 -fetoprotein and beta-human chorionic gonadotropin in infancy and childhood. Pediatr Hematol Oncol 2001;18:11-26.

9. Schneider DT, Calaminus G, Koch S, Teske C, Schmidt P, Haas RJ, et al. Epidemiologic analysis of 1,442 children and adolescents registered in the German germ cell tumor protocols. Pediatr Blood Cancer 2004;42:169-75.

10. Odagiri K, Omura M, Hata M, Aida N, Niwa T, Ogino I, et al. Treatment outcomes, growth height, and neuroendocrine functions in patients with intracranial germ cell tumors treated with chemoradiation therapy. Int J Radiat Oncol Biol Phys 2012;84:632-8. 